\title{
Intestinal absorption, organ distribution, and urinary excretion of the rare sugar D-psicose
}

This article was published in the following Dove Press journal:

Drug Design, Development and Therapy

17 October 2014

Number of times this article has been viewed

\section{Ikuko Tsukamoto',* \\ Akram Hossain ${ }^{2,3, *}$ \\ Fuminori Yamaguchi ${ }^{2}$ \\ Yuko Hirata ${ }^{2}$ \\ Youyi Dong² \\ Kazuyo Kamitori ${ }^{2}$ \\ Li Sui ${ }^{2}$ \\ Machiko Nonaka ${ }^{2}$ \\ Masaki Ueno ${ }^{4}$ \\ Kazuyuki Nishimoto ${ }^{5}$ \\ Hirofumi Suda ${ }^{5}$ \\ Kenji Morimoto 6 \\ Tsuyoshi Shimonishi ${ }^{7, \dagger}$ \\ Madoka Saito ${ }^{8}$ \\ Tao Song' \\ Ryoji Konishi' \\ Masaaki Tokuda ${ }^{2}$}

'Department of Pharmaco-Bio-Informatics, Faculty of Medicine, Kagawa University, Miki, Kagawa, Japan; ${ }^{2}$ Department of Cell Physiology, Faculty of Medicine, Kagawa University, Kagawa, Japan; ${ }^{3}$ Matsutani Chemical Industry Co, Ltd, Itami, Japan; ${ }^{4}$ Department of Inflammation Pathology, Faculty of Medicine,

Kagawa University, Kagawa, Japan; ${ }^{5}$ Division of Radioisotope Research, Life Science Research Center, Kagawa University, Kagawa, Japan; ${ }^{6}$ Rare Sugar Research Center, Kagawa University, Kagawa, Japan; ${ }^{\prime} I Z U M O R I N G$ LLC, Miki, Kita, Kagawa, Japan; ${ }^{8}$ Department of Pharmacy, Okayama University Hospital, Okayama, Japan; 'The First Affiliated Hospital, China Medical University, Shenyang, People's Republic of China

*These authors contributed equally to this work

†Tsuyoshi Shimonishi has passed away

Correspondence: Akram Hossain Department of Cell Physiology, Faculty of Medicine, Kagawa University, I750-I Ikenobe, Miki, Kita, Kagawa, 76I-0793 Japan

Tel +8I $8789 \mid 2095$

Fax +81878912096

Email hossain@med.kagawa-u.ac.jp
Background: The purpose of this study was to evaluate intestinal absorption, organ distribution, and urinary elimination of the rare sugar D-psicose, a 3-carbon stereoisomer of D-fructose that is currently being investigated and which has been found to be strongly effective against hyperglycemia and hyperlipidemia.

Methods: This study was performed using radioactive D-psicose, which was synthesized enzymatically from radioactive D-allose. Concentrations in whole blood, urine, and organs were measured at different time points until 2 hours after both oral and intravenous administrations and 7 days after a single oral administration $(100 \mathrm{mg} / \mathrm{kg}$ body weight $)$ to Wistar rats. Autoradiography was also performed by injecting $100 \mathrm{mg} / \mathrm{kg}$ body weight of ${ }^{14} \mathrm{C}$-labeled $\mathrm{D}$-psicose or glucose intravenously to $\mathrm{C} 3 \mathrm{H}$ mice.

Results: Following oral administration, D-psicose easily moved to blood. The maximum blood concentration $(48.5 \pm 15.6 \mu \mathrm{g} / \mathrm{g})$ was observed at 1 hour. Excretion to urine was $20 \%$ within 1 hour and $33 \%$ within 2 hours. Accumulation to organs was detected only in the liver. Following intravenous administration, blood concentration was decreased with the half-life $=57$ minutes, and the excretion to urine was up to almost $50 \%$ within 1 hour. Similarly to the results obtained with oral administration, accumulation to organs was detected only in the liver. Seven days after the single-dose oral administration, the remaining amounts in the whole body were less than $1 \%$. Autoradiography of mice showed results similar to those in rats. High signals of ${ }^{14} \mathrm{C}$-labeled D-psicose were observed in liver, kidney, and bladder. Interestingly, no accumulation of D-psicose was observed in the brain.

Conclusion: D-psicose was absorbed well after oral administration and eliminated rapidly after both oral and intravenous administrations, with short duration of action. The study provides valuable pharmacokinetic data for further drug development of D-psicose. Because the findings were mainly based on animal study, it is necessary to implement human trials to study the metabolism pathway, which would give an important guide for human intake and food application of D-psicose.

Keywords: ${ }^{14} \mathrm{C}$-labeled D-psicose, organ accumulation, pharmacokinetics, autoradiography

\section{Introduction}

Rare sugar D-psicose (also called D-allulose), whose unique effect against hyperglycemia and obesity which recently excited the people, has received intense attention from researchers as well as food companies as they aim to produce a variety of D-psicosecontaining, low-calorie foodstuffs for those with diabetic or obesity tendency, as a means of reducing the present high prevalence of these conditions. Rare sugars were defined as monosaccharides and their derivatives at the first international symposium of the International Society of Rare Sugars (ISRS), 2002, held in Takamatsu, Kagawa, 
Japan. ${ }^{1}$ Rare sugars are present in small quantities in commercial mixtures of D-glucose and D-fructose obtained from hydrolysis of sucrose or isomerization of D-glucose. ${ }^{2}$

D-psicose, an epimer of D-fructose isomerized at the C-3 position, is a rare ketohexose that can be derived in small amounts from wheat, ${ }^{3}$ itea plants, ${ }^{4}$ processed cane, and beet molasses. A trace amount of D-psicose is also detected in human urine ${ }^{5}$ and on the surface of human skin. ${ }^{6}$ Due to its rarity, the biological functions of D-psicose have not yet been sufficiently explored, but unique, innovative methods of production through Izumoring ${ }^{7,8}$ has enabled a number of investigations. ${ }^{9-18}$ It has been found experimentally to have dramatic effects against obesity and type 2 diabetes mellitus (T2DM) in normal ${ }^{11,14}$ as well as $\mathrm{T}^{2} \mathrm{DM}^{16-18}$ rat models, and clinically against hyperglycemia and hyperlipidemia in healthy ${ }^{13}$ and borderline diabetic humans, ${ }^{15}$ hence its use as a sugar substitute for obese and diabetic patients. As the mechanism of controlling high glucose levels, the potency of absorption of D-psicose over D-glucose from the intestine, ${ }^{19}$ as well as inhibition of activities of enzymes for the digestion of polysaccharides, such as glucoamylase and maltase, have been mentioned as possible reasons. ${ }^{14}$ D-psicose has also been shown to inhibit hepatic fatty acid synthase $\mathrm{e}^{20}$ by the mechanism of controlling adipose tissue deposition, followed by decreased body weight gain in comparison to D-glucose. In addition to the antihyperglycemic and antilipidemic effects of D-psicose, its zerocalorie credit and $70 \%$ relative sweetness have led food companies to prepare various foodstuffs using D-psicose as a substitute for sugar. Mainly to substitute sucrose by D-psicose for food production, due to D-psicose's high solubility, ${ }^{21}$ smooth texture ${ }^{22}$ and low glycemic response ${ }^{23}$ in comparison to sucrose, ${ }^{21}$ given that consumption of sugar-sweetened beverages has been increasingly associated with negative health outcomes such as overweight, obesity, T2DM, and metabolic syndrome. ${ }^{24}$ Based largely on these associations, many researchers and health care practitioners have proposed that non-caloric, high-intensity sweeteners provide a beneficial alternative to sugar in foods and beverages. ${ }^{25}$ D-psicose was approved as "Generally Recognized As Safe" (GRAS) by the US Food and Drug Administration (FDA) in August 2011 (GRN No 400), and it is allowed to be used as an ingredient in a range of foods and dietary supplements. ${ }^{26}$

In almost all the above-mentioned physiological studies, different doses of D-psicose were used to decide a nonhazardous therapeutic dose, since the pharmacokinetics are yet to be fully known, although they have been described to a small extent in the literature by Whistler et al. ${ }^{27}$ Moreover, for approval for food production in the industry as a safe food additive, the Japanese Ministry of Health, Labor and Welfare requires assessments of the degradability of D-psicose by fermentation and digestion/absorption studies. Whistler et $\mathrm{al}^{27}$ reported the metabolism of D-psicose in rats using $\mathrm{D}-\left[\mathrm{U}-{ }^{14} \mathrm{C}\right]$ psicose and measured the contents in urine, feces, glycogen, exhaled carbon dioxide, and carcasses 6-72 hours after oral and intravenous administrations. Research studies and human trials ${ }^{11,13,15,17,18}$ have shown high safety and efficacy of D-psicose against obesity and T2DM, but in addition to oral administration, injection is also needed for emergency purposes, therefore an oral formulation with therapeutic efficacy comparable with that of injection is important. As such, a study of the pharmacokinetic parameters of D-psicose is needed.

In this study, the pharmacokinetic parameters of D-psicose was investigated after oral and intravenous administrations in rats. Additionally, data on human studies will be accepted more widely and rapidly to the researchers. However, data from this animal study, as well as the ongoing double-blind human study, which is currently under strict supervision, will highlight the significance of D-psicose use.

\section{Materials and methods \\ Materials}

D-[1- $\left.{ }^{14} \mathrm{C}\right]$ allose $(37.2 \mathrm{mM} 3 \%$ ethanol solution, $1.96 \mathrm{GBq} / \mathrm{mmol})$ and $\mathrm{D}-\left[1-{ }^{14} \mathrm{C}\right]$ glucose $(0.654 \mathrm{mM} 0.3 \%$ EtOH solution, $11.3 \mathrm{GBq} / \mathrm{mmol}$ ) were obtained from Amersham Biosciences UK Ltd (Little Chalfont, Buckinghamshire, UK). Cold D-psicose, D-allose, and L-rhamnose isomerase immobilized beads were supplied by the Rare Sugar Research Center of Kagawa University (Miki, Kagawa, Japan). Carbo-Sorb ${ }^{\circledR} \mathrm{E}$ and Permafluor ${ }^{\circledR} \mathrm{E}^{+}$were from PerkinElmer, Inc., (Waltham, MA, USA).

\section{Animals}

This study was approved by the Animal Care and Use Committee of Kagawa University (permission number: 2013-45) and the experiment was conducted in accordance with the Institutional Guidelines and Rules for Care and Use of Laboratory Animals. Male Wistar rats $(\mathrm{n}=30)$, weighing 280-320 g, and male C3H mice $(\mathrm{n}=10)$, weighing 28-32 g, were purchased from Charles River Laboratories Japan, INC. (Yokohama, Japan) and housed for at least 7 days in a clean room in the animal facility of the Faculty of Medicine, Kagawa University. The rats were given free access to commercial chow and water, and were maintained according to the Kagawa University animal guidelines. 


\section{Biodistribution experiment}

All the rats used for both oral and intravenous D-psicose administration were fasted for 24 hours before surgery; on the experiment day, they were shifted to the radio isotope facility because of the use of radioactive D-allose and D-glucose. For intravenous administration, rats were anesthetized with an intraperitoneal injection of pentobarbital sodium (1\%), and a polyethylene catheter (Intramedic ${ }^{\mathrm{TM}} \mathrm{PE}-50$; Clay Adams, Parsippany, NJ, USA) was inserted into the femoral vein for D-psicose or vehicle administration. Anesthesia was continued until the end of the 120-minute experimental period, with further administration of small doses of diluted pentobarbital when needed. Oral administration was performed in awake rats by gavage using a metallic tube directly into the stomach. Approximately $0.6 \mathrm{~mL}$ psicose solution (30 mg, $120 \mathrm{kBq}$ ) was administered (dose: $100 \mathrm{mg} / \mathrm{kg}$ ) in both oral and intravenous administrations. Urine was collected from the urinary bladder by penis ligation.

The rats were sacrificed 10, 30, 60, and 120 minutes after administration. The weights of whole brain, thymus, lung, liver, heart, spleen, and kidney were measured. The amount of total urine in the urinary bladder was also measured. The contents in gastrointestinal (GI) organs (stomach, small intestine, large intestine, and cecum) were collected and homogenized.

\section{Sample oxidizer analysis}

From the collected specimens, a small quantity $(0.1-0.2 \mathrm{~g})$ of blood, skin, and muscle was weighed and then burned in a sample oxidizer (model 307; PerkinElmer). ${ }^{14} \mathrm{C}$ was recovered as $\mathrm{CO}_{2}$ with a $\mathrm{CO}_{2}$ absorber (Carbo-Sorb E). The radioactivity in the absorber was measured by a liquid scintillation counter (Aloca LSC-5100; Hitachi Aloka Medical, Ltd., Tokyo, Japan) with a scintillator (Permafluor $\mathrm{E}^{+}$). The recovery by the sample oxidizer, estimated by comparing the count of burned and unburned samples, was $97.3 \% \pm 2.8 \%$. In oral administration, the remaining amounts of administered dose 7 days after a single dose $(100 \mathrm{mg} / \mathrm{kg})$ were also measured.

\section{Autoradiography}

After fasting for 24 hours, mice were injected via tail vein with $20 \mathrm{kBq}(100 \mathrm{mg} / \mathrm{kg}$ body weight $)$ of ${ }^{14} \mathrm{C}$-labeled psicose or ${ }^{14} \mathrm{C}$-labeled glucose dissolved in saline $(0.2 \mathrm{~mL})$. Thirty minutes after the injection, mice were anesthetized with diethyl ether and perfused transcardially with $0.01 \mathrm{M}$ phosphate-buffered saline after cutting of the right auricle. The whole bodies of the animals were immersed in dry ice/ acetone and kept in a deep freezer at $-50^{\circ} \mathrm{C}$. Whole-body frozen sections $(40 \mu \mathrm{m})$ from the sagittal plane immersed in
$8 \%$ carboxymethylcellulose compound were prepared with an autocryotome (NA-500F; Nakagawa Seisakusho, Tokyo, Japan), dried at $-20^{\circ} \mathrm{C}$, then exposed to an imaging plate (BAS-IP MS2040; FUJIFILM Holdings Corporation, Tokyo, Japan) for 8 weeks.

\section{Statistics}

All experiments were performed at least three times. Mean values and standard error of the means were shown. Statistical differences between groups were analyzed by Student's $t$-test. A $P$-value less than 0.05 was considered to be statistically significant.

\section{Results}

\section{Synthesis of ${ }^{14} \mathrm{C}$-labeled D-psicose}

Prior to synthesis of the radioactive compound, the experimental condition was evaluated using cold material. Hot D-allose solution was diluted with the same amount of water (18.6 mM in $1.5 \%$ EtOH solution), and $400 \mu \mathrm{L}$ of the solution was incubated with L-rhamnose isomerase immobilized beads $\left(1 \mathrm{~mm}\right.$ in diameter) at $37^{\circ} \mathrm{C}$ for 72 hours. L-rhamnose isomerase catalyzes the isomerization between D-allose and D-psicose (enzyme "c" in Figure 1). The properties of enzyme immobilized beads have been described previously. ${ }^{28}$ Under these conditions, we confirmed that more than $50 \%$ of D-allose was converted to D-psicose. Synthesized D-psicose was separated by high-performance liquid chromatography (HPLC) with a Hitachi GL-C611, Gel Pack column with GL-C600 guard column operated by an L-6200 Intelligent Pump, L-2350 Column Oven, L-2490 radioisotope detector, and D-2500 Chromato-integrator (all manufactured by Hitachi Aloka Medical, Ltd., Tokyo, Japan) (sample volume $400 \mu \mathrm{L}$; mobile phase, distilled water; flow rate $1.0 \mathrm{~mL} / \mathrm{min}$; column temperature $60^{\circ} \mathrm{C}$ ). The eluent around the retention time of D-psicose (from 27 to 35 minutes) was collected, concentrated, and separated again with HPLC. Repeating these processes three times, we succeeded in removing the contamination of D-allose, and confirmed the purity to be over $99 \%$ by HPLC. Since 10.9 MBq of D-psicose was obtained, the yield $=20 \%$ from the starting material of $54.1 \mathrm{MBq}$ of D-allose. The specific radioactivity of ${ }^{14} \mathrm{C}$-labeled D-psicose was assumed to be the same as that of the starting material of ${ }^{14} \mathrm{C}$-labeled D-allose, ie, $1.96 \mathrm{GBq} / \mathrm{mmol}$.

For the animal experiment, we prepared a D-psicose solution (containing $50 \mathrm{mg}$ and $200 \mathrm{kBq} / \mathrm{mL}$ saline for rats, $15 \mathrm{mg}$ and $100 \mathrm{kBq} / \mathrm{mL}$ for mice) by mixing the synthesized hot and cold compounds. The solution was stored at $5^{\circ} \mathrm{C}$ until use. The doses for rats and mice were both $100 \mathrm{mg} / \mathrm{kg}$, which 


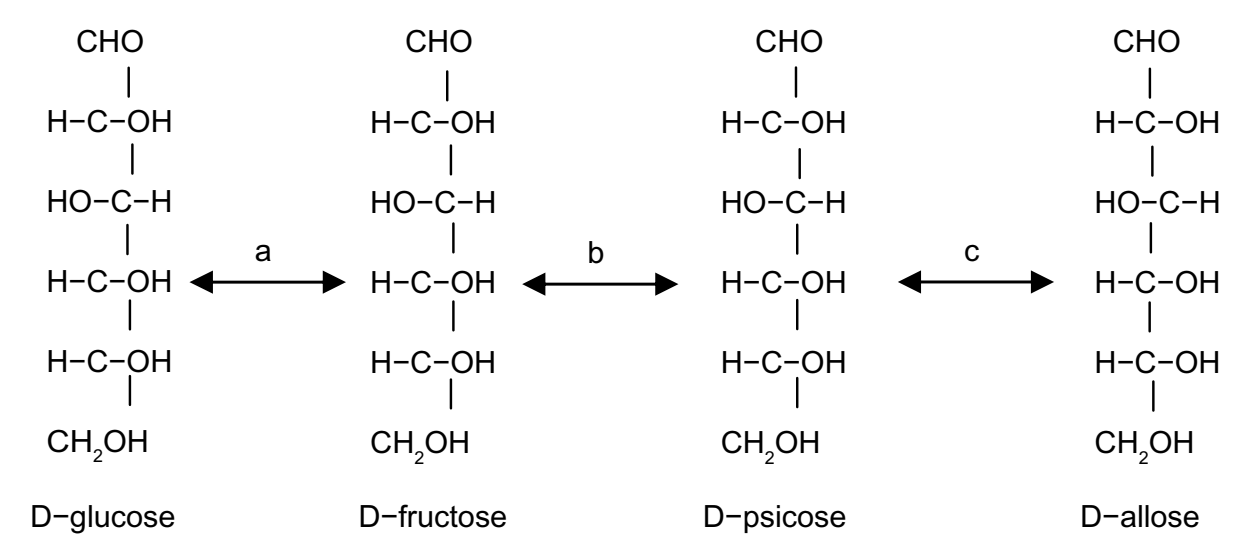

Figure I Structures and enzymatic conversion of D-glucose, D-fructose, D-psicose, and D-allose. Notes: Enzymes: $\mathrm{a}=$ glucose isomerase; $\mathrm{b}=\mathrm{D}$-tagatose 3 epimerase; $\mathrm{c}=$ L-rhamnose isomerase.

was decided from the effective dose used in a human study, which was $5 \mathrm{~g} /$ day. ${ }^{14}$

\section{Absorption and distribution of D-psicose after oral administration}

The absorption and distribution results of D-psicose after oral administration are summarized in Table 1 . Some of the orally administered D-psicose $(30,000 \mu \mathrm{g}$ in $0.6 \mathrm{~mL}$ saline) was easily absorbed from the intestine into blood and then excreted into urine. The concentrations of D-psicose in blood, evaluated by its radioactivity, were $11.3 \pm 6.4,41.8 \pm 16.2,48.5 \pm 15.6$, and $39.2 \pm 9.5 \mu \mathrm{g} / \mathrm{g}$ blood at $10,30,60$, and 120 minutes, respectively. The radioactivity of D-psicose and its concentrations in GI organs (stomach, small intestine, cecum, and large intestine) and their contents were approximately $20,814 \mu \mathrm{g}$ (69\%), 20,342 $\mu \mathrm{g}(67 \%), 15,032 \mu \mathrm{g}(50 \%)$, and 8,015 $\mu \mathrm{g}$ $(26 \%)$ at 10, 30, 60, and 120 minutes, respectively. D-psicose was not present in urine at 10 minutes, but started to appear at 30 minutes $(3,193.6 \pm 2,870.4 \mu \mathrm{g} ; 10 \%)$, and the amounts rapidly increased at 60 minutes $(5,832.0 \pm 1,682.5 \mu \mathrm{g} ; 19 \%)$ and 120 minutes $(11,125.2 \pm 2,403.0 \mu \mathrm{g} ; 37 \%)$. D-psicose levels in the liver were $41.4 \pm 28.7,126.3 \pm 45.0,200 \pm 86.3$, and $127.5 \pm 32.6 \mu \mathrm{g} / \mathrm{g}$ liver tissue at $10,30,60$, and 120 minutes, respectively. Other organs (lung, thymus, spleen, heart, brain, skin, and muscle) showed lower radioactivity, whereas kidney showed higher radioactivity $(74.0 \pm 54.5,287.0 \pm 217.8$, $395.3 \pm 147.1$, and $168.1 \pm 34.9 \mathrm{mg} / \mathrm{g}$ tissue at $10,30,60$, and 120 minutes, respectively).

The residual amount of D-psicose was measured 7 days after a single-dose oral administration $(100 \mathrm{mg} / \mathrm{kg})$. The results are shown in Table 2. Blood concentration of D-psicose estimated from the radioactivity was $1.4 \pm 0.9 \mu \mathrm{g} / \mathrm{g}$, which was much less than the value after 120 minutes $(39.2 \pm 9.5 \mu \mathrm{g} / \mathrm{g}$ [Table 1]). Organs that showed higher concentrations than blood were liver, kidney, lung, thymus, spleen, heart, skin, stomach, small intestine, cecum, and large intestine. On the other hand, levels in the GI contents and urine were very low 7 days after a single dose of D-psicose. As large organs, small intestine ( $4.70 \pm 0.38 \mathrm{~g}$ wet weight) and liver $(7.65 \pm 0.42 \mathrm{~g}$ wet weight) contained 54.3 and $44.5 \mu \mathrm{g} /$ organ D-psicose, respectively. Radioactivity of muscle was $1.2 \mu \mathrm{g} / \mathrm{g}$ tissue, although, as a large organ, the total content was not considered high. The radioactivity of skin was low, but higher than blood.

\section{Absorption and distribution of D-psicose after intravenous administration}

The concentration and total contents of D-psicose after intravenous administration are summarized in Table 3. Radioactivity of D-psicose concentration in blood was $132.0 \pm 22.1,83.0 \pm 26.5,77.2 \pm 23.5$, and $40.1 \pm 31.5 \mu \mathrm{g} / \mathrm{g}$ blood at 10,30,60, and 120 minutes, respectively, after intravenous administration of isotope-labeled D-psicose. Concentrations in liver and kidney remained higher than concentrations in blood throughout the experiment. The concentrations in the liver were $348.6 \pm 56.8,354.3 \pm 32.1,322.0 \pm 96.3$, and $139.4 \pm 52.8 \mu \mathrm{g} / \mathrm{g}$ liver tissue at $10,30,60$, and 120 minutes, respectively, and those in kidney were $868.9 \pm 202.6$, $649.8 \pm 175.0,462.9 \pm 183.7$, and $243.8 \pm 101.5 \mu \mathrm{g} / \mathrm{g}$ tissue at $10,30,60$, and 120 minutes, respectively. Radioactivity of D-psicose in urine was 4,773.6 $\pm 1,376.6,7,303.9 \pm 3,662.3$, $13,230.7 \pm 3,292.9$, and $15,231.7 \pm 4,649.0 \mu \mathrm{g} / \mathrm{unit}$ at 10 , 30,60 , and 120 minutes, respectively. It was found that the administered D-psicose eliminated quickly from blood and moved to the urine. Of the total administered dose $(30,000 \mu \mathrm{g})$, approximately $1 / 6(15 \%),{ }_{4}^{1 /}(24 \%),{ }_{5} / 5(44 \%)$, and $1 / 2(50 \%)$ were eliminated into urine at $10,30,60$, and 120 minutes, respectively (Table 3 ). However, the high concentration in kidney was assumed to be the ${ }^{14} \mathrm{C}$-labeled 


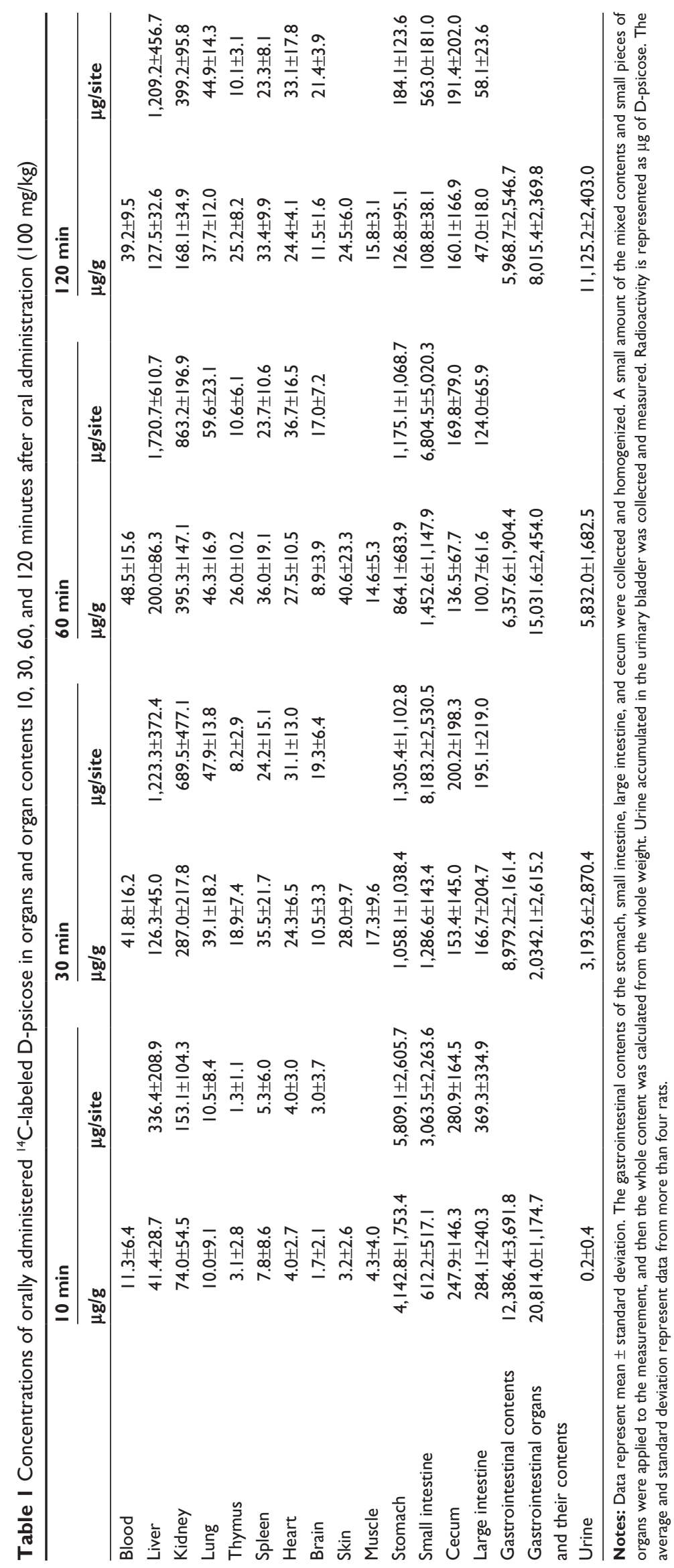


Table 2 Concentrations of orally administered I4C-labeled D-psicose in organs and organ contents 7 days after oral administration $(100 \mathrm{mg} / \mathrm{kg})$

\begin{tabular}{llr}
\hline & $\mu g / g$ & $\mu g / s i t e$ \\
\hline Blood & $1.4 \pm 0.9$ & \\
Liver & $5.0 \pm 1.2$ & $44.5 \pm 9.2$ \\
Kidney & $5.7 \pm 1.2$ & $12.1 \pm 2.5$ \\
Lung & $3.6 \pm 1.8$ & $3.9 \pm 2.0$ \\
Thymus & $9.0 \pm 3.7$ & $5.6 \pm 5.2$ \\
Spleen & $3.8 \pm 0.9$ & $2.7 \pm 0.8$ \\
Heart & $2.7 \pm 0.6$ & $2.7 \pm 0.8$ \\
Brain & $1.5 \pm 0.4$ & $2.9 \pm 0.7$ \\
Skin & $4.9 \pm 1.5$ & \\
Muscle & $1.2 \pm 0.8$ & \\
Stomach & $3.8 \pm 1.1$ & $5.8 \pm 2.1$ \\
Small intestine & $9.4 \pm 2.6$ & $54.3 \pm 14.8$ \\
Cecum & $6.1 \pm 2.6$ & $8.9 \pm 4.6$ \\
Large intestine & $6.6 \pm 1.2$ & $8.1 \pm 4.1$ \\
Gastrointestinal contents & & $8.9 \pm 6.5$ \\
Urine & $0.6 \pm 0.5$ & $0.4 \pm 0.4$ \\
Gastrointestinal organs & & $86.0 \pm 17$ \\
and their contents & &
\end{tabular}

Notes: Data represent mean \pm standard deviation. A single dose of $100 \mathrm{mg} / \mathrm{kg}$ body weight D-psicose was administered to rats. Seven days after administration, the radioactivity in each organ was measured and is represented as $\mu \mathrm{mol}$ of $D$-psicose/g. The mean and standard deviation are shown for more than four independent experiments.

D-psicose-containing urine in the kidney. On the other hand, other organs examined (lung, thymus, spleen, heart, brain, skin, muscle, stomach, small intestine, cecum, and large intestine) showed lower radioactivity than the blood. As shown in Table 3, the sum of D-psicose contents in GI organs (stomach, small intestine, cecum, large intestine) and their contents was very small. The concentration change of D-psicose in blood is shown in Figure 2. From the inclination of the logarithmic plot of the data of this profile, the half-life was estimated to be 57.3 minutes.

\section{Autoradiography}

Autoradiograms are shown in Figure 3. As intravascular blood was washed out with $0.01 \mathrm{M}$ phosphate-buffered saline, the radioactivity of intravascular blood may be very small and thus negligible. Similarly to the results obtained with rats, high signals of ${ }^{14} \mathrm{C}$-labeled D-psicose were observed in liver, kidney, and bladder. Interestingly, no accumulation of D-psicose was seen in the brain, while a large amount of D-glucose was detected there.

\section{Discussion}

Orally administered D-psicose $(30,000 \mu \mathrm{g}$ in $0.6 \mathrm{~mL}$ saline $)$ absorbed partly from the GI tract into the blood and was then excreted into urine. Radioactivity of D-psicose in
GI contents decreased gradually over 120 minutes, with simultaneous increase in both GI organs and blood, peaked at 10 minutes in GI organs and 60 minutes in the blood, and then decreased in both contents and organs decreased gradually over 120 minutes (Table 1). In rat GI organs, D-psicose can be metabolized by intestinal microorganisms. Matsuo et al demonstrated that, after oral administration, D-psicose disappeared from stomach, small intestine, and serum in 1-7 hours, peaked at 1 hour, but did not decrease in the rat cecum even 7 hours after administration. ${ }^{29}$ Since D-psicose did not disappear from the caecum, in favor of this they found increased cecal weight and surface area as a result of the presence of short chain fatty acids, the fermented products of D-psicose by intestinal microflora in the cecal contents, similar to other soluble dietary fibers or polydextrose..$^{30,31} \mathrm{D}$-psicose that did not absorb in small intestine transferred to large intestine and was found fermented in the appendix, which was confirmed by continuous administration of D-psicose that increased short-chain fatty acids within the appendix, suggesting that D-psicose is fermented in the appendix of rats to a certain extent. ${ }^{28}$ Matsuo et al also reported that the unfermented D-psicose was rapidly excreted in feces, where $8 \%-13 \%$ of the dosage was recovered within the first 24 hours. ${ }^{29}$ These results suggest that a large percentage of administered D-psicose remains in the rat body or is oxidized by the animal's metabolic system. Since D-psicose provides no energy to growing rats, most of the D-psicose remaining in the rat body is probably fermented by bacteria in the cecum or large intestine ${ }^{29}$ Iida et al reported clinical metabolism studies in humans that demonstrated that D-psicose failed to be absorbed in the small intestine to metabolize into energy and showed low fermentability by intestinal bacteria in the large intestine. ${ }^{13}$ However, most of the D-psicose absorbed was eliminated from the blood and was rapidly excreted into urine. The radioactivity in urine at 120 minutes was $37.1 \% \pm 8.0 \%$ of the administered dosage and, at 7 days after administration, was almost $0 \%$. Matsuo et al detected $11 \%-15 \%$ of D-psicose after 24 hours and could not detect any D-psicose after 24-48 hours of administration..$^{29}$ In another study, undertaken many years ago, Whistler et al reported that $35.4 \%$ of orally administered D-psicose was excreted into urine within 7 hours. ${ }^{27}$ However, since there are very few studies in the literature on the absorption and distribution of D-psicose, as well as variability of detection times among studies that are reported, ${ }^{27,29}$ we cannot claim that our study is strongly consistent with others, ${ }^{27,29}$ but we can report that our findings regarding easy absorption from the digestive tract and early excretion from blood to urine are consistent with other findings. Recently, 


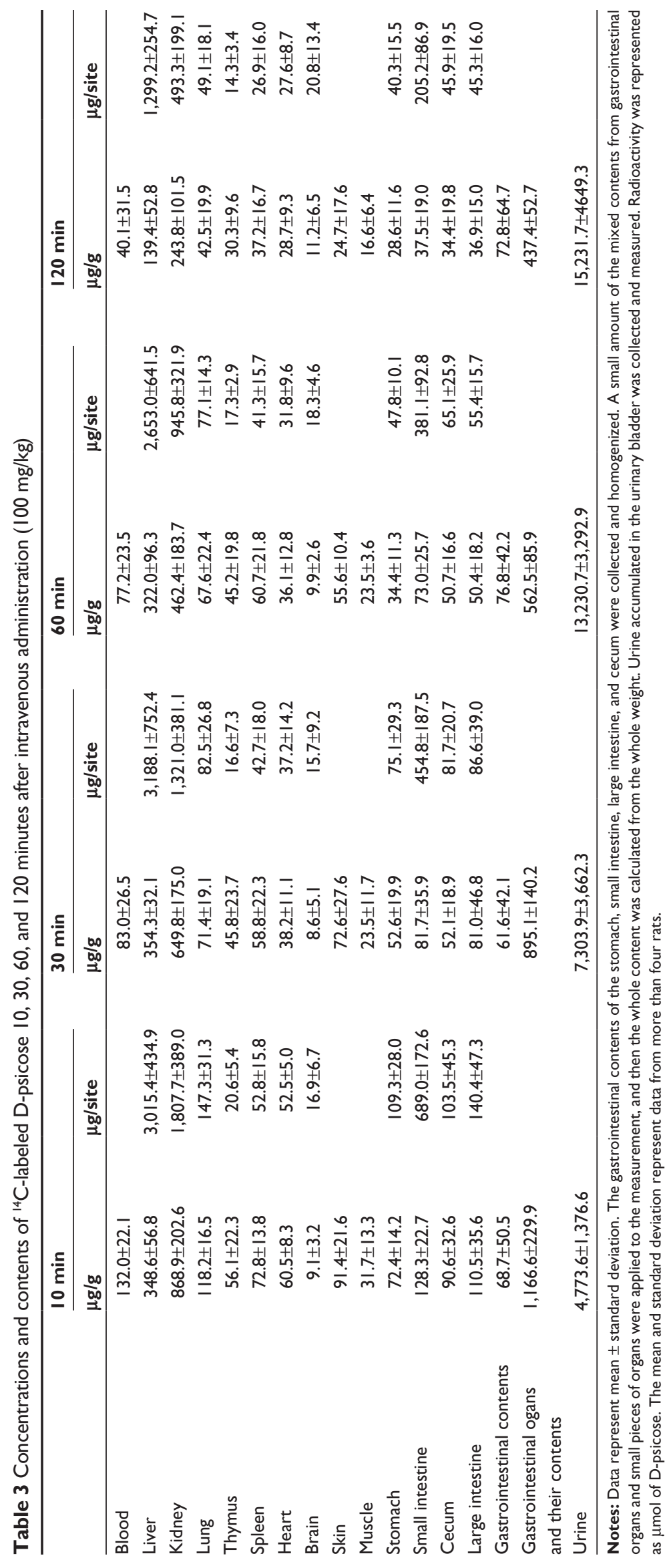




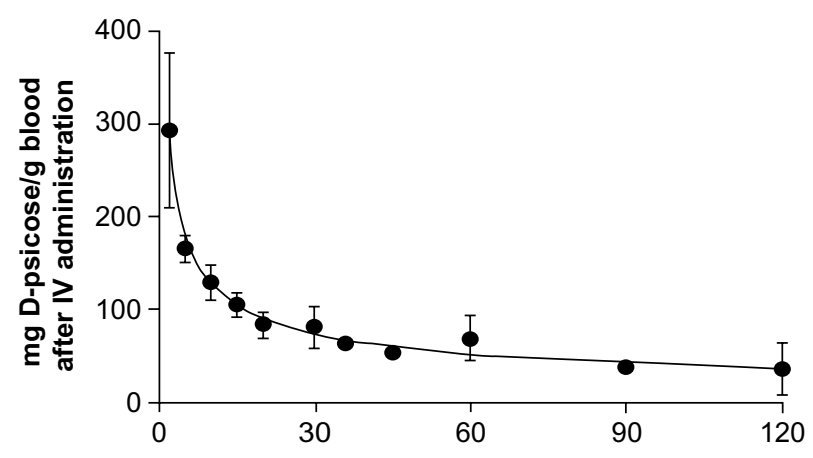

Figure 2 Time dependence of the blood concentration of intravenously administered D-psicose.

Notes: Whole blood was collected from the femoral vein $(0.1-0.2 \mathrm{~g})$ and its radioactivity was measured. Radioactivity is presented as $\mu \mathrm{g}$ of D-psicose/g. The average and standard deviation from the data of 27 rats are shown.

Abbreviation: IV, intravenous.

Hishiike et al studied the absorption of D-psicose through human intestine using Caco-2 cell monolayer, and compared its absorption with that of glucose and fructose. ${ }^{19}$ Hishiike et al showed very clearly that D-psicose was transported from the intestinal lumen into the intestinal enterocytes by a glucose transporter, GLUT5, and from the enterocytes into the circulation by another transporter, GLUT2. ${ }^{19}$ They also concluded that the coexistence of glucose with psicose induced a $60 \%$ decrease in the glucose permeability. This might be one of the important mechanisms of D-psicose's antihyperglycemic effect, which has been proven by several animal ${ }^{11,13,16-18}$ and clinical ${ }^{13,15}$ studies. The advantages for people who are obese or have obese tendencies, as well as for diabetic people, of added D-psicose over added sugar in foodstuffs have been elucidated. ${ }^{22,32}$ There is no doubt that replacing caloric with non-caloric sweeteners reduces the energy density of foods and beverages. ${ }^{33}$ Increased consumption of high-fructose corn syrup (HFCS) in beverages has paralleled increases in the prevalence of obesity and
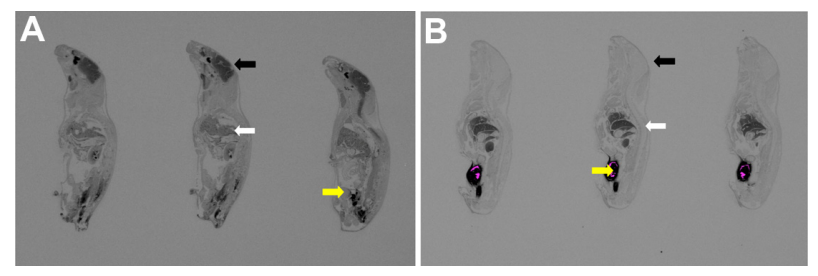

Figure 3 Typical autoradiograms of $\mathrm{C} 3 \mathrm{H}$ mice.

Notes: Mice were injected with $20 \mathrm{kBq}(3 \mathrm{mg})$ of ${ }^{14} \mathrm{C}$-labeled glucose $(\mathrm{n}=3)(\mathbf{A})$ and ${ }^{14} \mathrm{C}$-labeled psicose $(\mathrm{n}=3)(\mathbf{B})$ dissolved in saline $(0.2 \mathrm{~mL})$ through the tail vein. Thirty minutes after injection, mice were anesthetized with diethyl ether and perfused transcardially with $0.01 \mathrm{M}$ phosphate-buffered saline after cutting of the right auricle. Whole-body frozen sections $(40 \mu \mathrm{m})$ at sagittal plane were prepared, then exposed to an imaging plate for 8 weeks. Signals of ${ }^{14} \mathrm{C}$-labeled psicose were observed in liver (white arrows) and urinary bladder (yellow arrows), but no signal was observed in the brain (black arrows), whereas a signal of ${ }^{14} \mathrm{C}$-labeled glucose was observed in the brains of all mice. metabolic syndrome, and is associated with the appearance of nonalcoholic fatty liver disease. ${ }^{34}$ In a comparison study of HFCS and rare sugar syrup (a modified form of HFCS containing about $6 \%$ rare sugar D-psicose), Iida et al confirmed the reduction of HFCS-induced obesity by D-psicose, finding significant decreases in body weight as well as intraabdominal adipose tissue weight after feeding diets containing HFCS or rare sugar syrup for 90 days. ${ }^{35} \mathrm{~A}$ study has shown that a high-sucrose diet or sucrose supplementation can produce hyperlipidemia, obesity, and insulin resistance, and that addition of 5\% D-psicose in a high-sucrose diet significantly suppressed body fat accumulation in adult rats. ${ }^{36}$ Several other studies have also reported that plasma glucose levels in the postprandial state are significantly suppressed by D-psicose in rats. ${ }^{11,14,16}$ One study also suggested that, compared with $5 \% \mathrm{D}$-fructose or D-glucose, $5 \%$ dietary D-psicose reduced body fat accumulation through inhibiting lipogenesis in liver and adipose tissue.$^{20}$ In a recent comparison of D-psicose and D-glucose, we showed that D-psicose served as a unique metabolic regulator in the growing type T2DM Otsuka Long-Evans Tokushima Fatty rats through the maintenance of blood glucose and prevention of abdominal fat deposition. ${ }^{17}$ For low index through foods which eventually will prevent lifestyle-related disease, Iida et al performed a clinical oral glucose tolerance test with $75 \mathrm{~g}$ maltodextrin load with or without different doses $(2.5 \mathrm{~g}, 5 \mathrm{~g}$, and $7.5 \mathrm{~g})$ of D-psicose and confirmed the dose-dependent suppression of high blood glucose levels induced by maltodextrin. ${ }^{13}$ However, many researchers have noted slight increases of liver weight with D-psicose feeding in animals. ${ }^{37-39}$ This might be due to multiple activities of D-psicose in the liver, including increased hepatic glycogen content, ${ }^{32}$ which can cause high radioactivity in the liver. Whistler et al also reported that liver glycogen contained $1.0 \%$ of the radioactivity 6 hours after intravenous D-psicose injection. ${ }^{27}$

Table 2 shows the residual amounts of D-psicose 7 days after single-dose oral administration $(100 \mathrm{mg} / \mathrm{kg})$. The radioactivity in the GI contents as well as in urine was almost zero, suggesting that excretion from the digestive tract was almost finished. All organs showed some radioactivity; the thymus is a comparatively small organ (compared to others), but radioactivity of D-psicose in the thymus was high, the reason for which is unknown. However, collectively, the total remaining content did not exceed $300 \mu \mathrm{g}$. Of the total administered dose $(30,000 \mu \mathrm{g})$, more than $99 \%$ of orally administered D-psicose was excreted within 7 days. This is very much consistent with the results of the study undertaken by Whistler et al, ${ }^{27}$ who detected $26 \%$ radioactivity 
as exhaled carbon dioxide and $95 \%$ radioactivity in the urine within 7 hours, where at least $70 \%$ was recovered as D-psicose and the remaining 30\% was associated with unidentified products of metabolism.

In the present study, intravenously administered D-psicose was eliminated quickly from blood and moved to the urine. Of the total $30,000 \mu \mathrm{g}$ dose of D-psicose administered, approximately $1 /{ }_{6}(4,770 \pm 1,380 \mu \mathrm{g})$, $1 / 4(7,300 \pm 3,660 \mu \mathrm{g}), 2 /{ }_{5}(13,230 \pm 3,290 \mu \mathrm{g})$, and $1 / 2$ $(15,230 \pm 4,650 \mu \mathrm{g})$ were eliminated into urine at 10,30 , 60 , and 120 minutes, respectively. Therefore, the high concentration into kidney was assumed to be the ${ }^{14} \mathrm{C}$-labeled D-psicose-containing urine remaining in the kidney. The accumulation of D-psicose in the liver was therefore suggested. Whistler et al reported that $97 \%-98 \%$ of the intravenously administered D-psicose was excreted into urine and only $0.6 \%$ was exhaled as carbon dioxide within 6 hours. These results indicate that intravenously administered D-psicose is rapidly removed by the kidney and is metabolized to only a small degree. ${ }^{27}$

\section{Conclusion}

We evaluated the accumulation of D-psicose in organs, and confirmed that no organ, except liver, accumulated D-psicose. The radioactivity of D-psicose was almost entirely excreted within 7 days. During the process, most of the administered D-psicose passed through the liver and kidney. Stress on these organs should be considered for the safe usage of D-psicose in humans. However, the fact that almost no radioactivity was detected in the brain suggested that D-psicose may not be able to pass the blood-brain barrier; fructose, a C-3 epimer of D-psicose, also does not pass the blood-brain barrier. ${ }^{40}$ This provides important evidence that indicates that D-psicose does not have a direct effect on the brain, even if excess amounts of D-psicose are taken into the body, either by oral or intravenous administration. Taking all considerations together, this study provides valuable pharmacokinetic data for drug development in addition to the preparation of healthy foods with rare sugar D-psicose.

\section{Disclosure}

The authors report no conflicts of interest in this work.

\section{References}

1. Hossain MA, Goda F, Izuishi K, Maeta H. Protective effects of D-allose agianst ischemia-reperfusion injury of rat liver. The 1 st symposium of international society of rare sugars. May 23-27, Kagawa, Japan.

2. Cree GM, Perlin AS. O-isopropylidene derivatives of D-allulose (D-psicose) and D-erythro-hexopyranos-2,3-diulose. Can J Biochem. 1968;46:765-770.
3. Miller BS, Swain T. Chromatographic analysis of the free amino-acids, organic acids and sugars in wheat plant extracts. J Sci Food Agric. 1960;11:344-348.

4. Hough L, Stacey BE. Variation in the allitol content of Itea plants during photosynthesis. Phytochemistry. 1966;5:171-175.

5. Strecker G, Goubet B, Montreuil J. The ketoses of human urine. Identification of D (+)-allulose. C R Hebd Seances Acad Sci. 1965;260:9991002. French. C R Acad Sc Paris. 1965;260:999-1003. French.

6. Padberg G. Über die Kohlenhydrate im wäßrigen Eluat der menschlichen Hautoberfläche [On the carbohydrates in the water eluate of the human skin surface]. Arch Klin Exp Dermatol. 1967;229:33-39. German.

7. Takeshita K, Suga A, Takada G, Izumori K. Mass production of D-psicose from d-fructose by a continuous bioreactor system using immobilized D-tagatose 3-epimerase. J Biosci Bioeng. 2000;90:453-455.

8. Granström TB, Takata G, Tokuda M, Izumori K. Izumoring: a novel and complete strategy for bioproduction of rare sugars. J Biosci Bioeng. 2004;97:89-94.

9. Matsuo T, Suzuki H, Hashiguchi M, Izumori K. D-Psicose is a rare sugar that provides no energy to growing rats. J Nutr Sci Vitaminol (Tokyo). 2002;48:77-80.

10. Murata A, Sekiya K, Watanabe Y, et al. A novel inhibitory effect of $\mathrm{D}$-allose on production of reactive oxygen species from neutrophils. J Biosci Bioeng. 2003;96:89-91.

11. Matsuo T, Izumori K. Effects of dietary D-psicose on diurnal variation in plasma glucose and insulin concentrations of rats. Biosci Biotechnol Biochem. 2006;70:2081-2085.

12. Suna S, Yamaguchi F, Kimura S, Tokuda M, Jitsunari F. Preventive effect of D-psicose, one of rare ketohexoses, on di-(2-ethylhexyl) phthalate (DEHP)induced testicular injury in rat. Toxicol Lett. 2007;173:107-117.

13. Iida T, Kishimoto Y, Yoshikawa Y, et al. Acute D-psicose administration decreases the glycemic responses to an oral maltodextrin tolerance test in normal adults. J Nutr Sci Vitaminol (Tokyo). 2008;54: 511-514.

14. Matsuo T, Izumori K. d-Psicose inhibits intestinal alpha-glucosidase and suppresses the glycemic response after ingestion of carbohydrates in rats. J Clin Biochem Nutr. 2009;45:202-206.

15. Hayashi N, Iida T, Yamada T, et al. Study on the postprandial blood glucose suppression effect of D-psicose in borderline diabetes and the safety of long-term ingestion by normal human subjects. Biosci Biotechnol Biochem. 2010;74:510-519.

16. Baek SH, Park SJ, Lee HG. D-psicose, a sweet monosaccharide, ameliorate hyperglycemia, and dyslipidemia in C57BL/6J db/db mice. J Food Sci. 2010;75:H49-H53.

17. Hossain MA, Kitagaki S, Nakano D, et al. Rare sugar D-psicose improves insulin sensitivity and glucose tolerance in type 2 diabetes Otsuka Long-Evans Tokushima Fatty (OLETF) rats. Biochem Biophys Res Commun. 2011;405:7-12.

18. Hossain A, Yamaguchi F, Matsunaga T, et al. Rare sugar D-psicose protects pancreas $\beta$-islets and thus improves insulin resistance in OLETF rats. Biochem Biophys Res Commun. 2012;425:717-723.

19. Hishiike T, Ogawa M, Hayakawa S, et al. Transepithelial transports of rare sugar D-psicose in human intestine. J Agric Food Chem. 2013;61(30):7381-386.

20. Matsuo T, Baba Y, Hashiguchi M, Takeshita K, Izumori K, Suzuki H. Dietary D-psicose, a C-3 epimer of D-fructose, suppresses the activity of hepatic lipogenic enzymes in rats. Asia Pac J Clin Nutr. 2001;10:233-237.

21. Oshima H, Kimura I, Izumori K. Psicose contents in various food products and its origin. Food Science and Technology Research. 2006;12(2): $137-143$.

22. Sun Y, Hayakawa S, Ogawa M, Fukada K, Izumori K. Influence of a rare sugar, d-Psicose, on the physicochemical and functional properties of an aerated food system containing egg albumen. J Agric Food Chem. 2008;56(12):4789-4796.

23. Fukada K, Ishii T, Tanaka K, et al. Crystal structure, solubility, and mutarotation of the rare monosaccharide D-psicose. Bull Chem Soc Jpn. 2010;83:1193-1197. 
24. Malik VS, Popkin BM, Bray GA, Després JP, Willett WC, Hu FB. Sugar-sweetened beverages and risk of metabolic syndrome and type 2 diabetes: a meta-analysis. Diabetes Care. 2010;33(11):2477-2483.

25. Gardner C, Wylie-Rosett J, Gidding SS, et al; American Heart Association Nutrition Committee of the Council on Nutrition, Physical Activity and Metabolism, Council on Arteriosclerosis, Thrombosis and Vascular Biology, Council on Cardiovascular Disease in the Young, and the American D. Nonnutritive sweeteners: current use and health perspectives: a scientific statement from the American Heart Association and the American Diabetes Association. Circulation. 2012;126(4):509-519.

26. Mu W, Zhang W, Feng Y, Jiang B, Zhou L. Recent advances on applications and biotechnological production of D-psicose. Appl Microbiol Biotechnol. 2012;94:1461-1467.

27. Whistler RL, Singh PP, Lake WC. D-Psicose metabolism in the rat. Carbohydr Res. 1974;34:200-202.

28. Morimoto K, Park CS, Ozaki M, et al. Large scale production of D-allose from D-psicose using continuous bioreactor and separation system. Enzyme Microb Technol. 2006;38:855-859.

29. Matsuo T, Tanaka T, Hashiguchi M, Izumori K, Suzuki H. Metabolic effects of D-psicose in rats: studies on faecal and urinary excretion and caecal fermentation. Asia Pac J Clin Nutr. 2003;12(2):225-231.

30. Figdor SK, Rennhard HH. Caloric utilization and disposition of [14C] polydextrose in the rat. J Agric Food Chem. 1981;29:1181-1189.

31. Topping DL, Clifton PM. Short-chain fatty acids and human colonic function: roles of resistant starch and nonstarch polysaccharides. Physiol Rev. 2001;81:1031-1064.
32. Sun Y, Hayakawa S, Izumori K. Modification of ovalbumin with a rare ketohexose through the Maillard reaction: effect on protein structure and gel properties. J Agric Food Chem. 2004;52:1293-1299.

33. Swithers SE. Artificial sweeteners produce the counterintuitive effect of inducing metabolic derangements. Trends Endocrinol Metab. 2013;24(9):431-441.

34. Dekker MJ, Su Q, Baker C, Rutledge AC, Adeli K. Fructose: a lighly lipogenic nutrient implicated insulin resistance, hepatic steatosis and the metabolic syndrome. Am J Physiol Endocrinol Metab. 2010;299:E685-E694.

35. Iida T, Yamada T, Hayashi N, et al. Reduction of abdominal fat accumulation in rats by 8-week ingestion of a newly developed sweetener made from high fructose corn syrup. Food Chem. 2013;138:781-785.

36. Ochiai M, Onishi K, Yamada T, Iida T, Matsuo T. D-psicose increases energy expenditure and decreases body fat accumulation in rats fed a high-sucrose diet. Int J Food Sci Nutr. 2014;65(2):245-250.

37. Yagi K, Matsuo T. The study on long-term toxicity of D-psicose in rats. $J$ Clin Biochem Nutr. 2009;45:271-277.

38. Matsuo T, Reika Ishii, Tetsuo Iida, Takako Yamada, Satoshi Tamamine and Yoko Shirai. Ninety-day oral toxicity study of rare sugar syrup in male Wistar rats. Current topics in toxicology 2011;7:41-50.

39. Matsuo T, Ishii R, Shirai Y. The 90-day oral toxicity of D-psicose in male Wistar rats. J Clin Biochem Nutr. 2012;50:158-161.

40. Oldendorf WH. Brain uptake of radiolabeled amino acids, amines, and hexoses after arterial injection. Am J Physiol. 1971;221:1629-1639.
Drug Design, Development and Therapy

\section{Publish your work in this journal}

Drug Design, Development and Therapy is an international, peerreviewed open-access journal that spans the spectrum of drug design and development through to clinical applications. Clinical outcomes, patient safety, and programs for the development and effective, safe, and sustained use of medicines are a feature of the journal, which

\section{Dovepress}

has also been accepted for indexing on PubMed Central. The manuscript management system is completely online and includes a very quick and fair peer-review system, which is all easy to use. Visit http://www.dovepress.com/testimonials.php to read real quotes from published authors.

Submit your manuscript here: http://www.dovepress.com/drug-design-development-and-therapy-journal 